\title{
Electricity grid tariffs as a tool for flexible energy systems: A Danish case study
}

\author{
Bergaentzlé, Claire; Jensen, Ida Græsted; Skytte, Klaus; Olsen, Ole Jess
}

Published in:
Energy Policy

Link to article, DOI:

10.1016/j.enpol.2018.11.021

Publication date:

2019

Document Version

Peer reviewed version

Link back to DTU Orbit

Citation (APA):

Bergaentzlé, C., Jensen, I. G., Skytte, K., \& Olsen, O. J. (2019). Electricity grid tariffs as a tool for flexible energy systems: A Danish case study. Energy Policy, 126, 12-21. https://doi.org/10.1016/j.enpol.2018.11.021

\section{General rights}

Copyright and moral rights for the publications made accessible in the public portal are retained by the authors and/or other copyright owners and it is a condition of accessing publications that users recognise and abide by the legal requirements associated with these rights.

- Users may download and print one copy of any publication from the public portal for the purpose of private study or research.

- You may not further distribute the material or use it for any profit-making activity or commercial gain

- You may freely distribute the URL identifying the publication in the public portal 


\title{
Electricity grid tariffs as a tool for flexible energy
}

\section{systems: a Danish case study}

Claire Bergaentzlé, ${ }^{\mathrm{a}^{*}}$ Ida Græsted Jensen, ${ }^{\mathrm{a}}$ Klaus Skytte ${ }^{\mathrm{b}}$ and Ole Jess Olsen ${ }^{\mathrm{c}}$

\begin{abstract}
*Corresponding author. E-mail address: clberg@dtu.dk
a Postdoctoral Fellow, Denmark Technical University, Management Engineering. Produktionstorvet, Building 42, 2800 Kgs. Lyngby. idje@dtu.dk

${ }^{\mathrm{b}}$ Head of Energy Economics and Regulation Group, Denmark Technical University, Management

Engineering. klsk@dtu.dk

${ }^{\mathrm{c}}$ Professor Emeritus, Denmark Technical University, Management Engineering. oleo@dtu.dk
\end{abstract}

\begin{abstract}
Electricity grid tariffs are a lever for reinforcing the coupling of district heating systems to the electricity system and for activating flexibility from power-to-heat $(\mathrm{P} 2 \mathrm{H})$ technologies and storage capacities. This study assesses three tariffs that permit a flexible use of electric boilers in a representative district heating system in Denmark. A mixed integer programming model is developed to evaluate the impact of each tariff on district heating flexibility quantitatively. The tariffs are then discussed in the light of the regulatory requirements that network tariffs must comply with.

We show that alternative tariffs enhance the business case for $\mathrm{P} 2 \mathrm{H}$ technologies to run flexibly, support the replacement of fossil fuels by green electricity and lower the overall cost of supplying heat. The attributes of each tariff create significant trade-offs between simplicity of implementation, cost efficiency at the distribution-grid level and cost-recovery for distribution system operators. Ultimately, new tariffs should be designed based on the characteristics of their respective groups of users in acknowledging features such as flexibility potential, substitutability between energy sources and captivity.
\end{abstract}

Keywords: flexibility; dynamic grid tariff; district heating; regulatory principles; electrification 


\section{Introduction}

The European Union has set ambitious decarbonization targets involving a drastic increase in renewable sources of energy and the progressive phasing out of polluting resources in energy systems. In the electricity sector, this objective results in increasing the share of variable renewable energies (VREs) in final electricity consumption (IRENA 2018) and urges that new flexibility solutions be found. Recent developments in the field of smart grids have highlighted the need to incentivize final electricity consumers to be responsive to signals from the electricity market and to adjust to the system's needs. However, this electricity sectorcentred approach often disregards other large flexibility potentials across energy systems. In Europe electricity consumption accounts for $18 \%$ of final energy consumption, compared with $32 \%$ for transportation and $50 \%$ for heating and cooling. It is consequently essential to use a cross-sectoral approach to investigate decarbonization in order to benefit from the existing synergies across systems. The coupling between electricity and district heating systems, in improving the business case for electric boilers, gives access to low cost flexibility potentials, capable of absorbing VRE energy peaks from the electricity sector and benefiting the heat sector in increasing the share of green energy used in heat generation.

Today, considerable flexibility potential exists from power-to-heat technologies $(\mathrm{P} 2 \mathrm{H})$ such as electric boilers in district heating (Kirkerud et al. 2017). Because district heating operators are small industrial consumers, they are more responsive to energy price variations than smaller consumers (Patrick and Wolak 1997; Borenstein et al. 2002; Dupont et al. 2014; Lund et al. 2015) and should be incentivized to participate actively in producing system efficiency.

District heating systems with diversified heat technologies provide a large portfolio of flexibility solutions due to their heat generation mix, usually based on a combination of $\mathrm{P} 2 \mathrm{H}$, combined heat and power plants (CHPs) and heat-only boilers (Sneum et al. 2016, Lislebø et al. 2011). P2H units use electricity to generate heat when electricity prices are low. CHPs are activated when electricity prices are high enough in the wholesale market to cover their operational costs. CHPs have fast-ramping capabilities and are complementary to $\mathrm{P} 2 \mathrm{H}$ units. The possibility to store water in tanks augments the contribution of both technologies to flexibility. Heat-only boilers powered by fossil fuels or biomass are disconnected from the electricity system and are a suitable technology for times when flexibility is not needed.

In spite of its large flexibility potential, system coupling is weak and flexibility resources are poorly exploited. Efficiently coupling the heat and electricity sectors must be holistic in scope (Lund et al. 2015; 
Lund \& Kempton 2008). While Bergaentzle et al. (2017) show that adapted fiscal policies and electricity grid tariffs are important framework conditions enabling flexibility across sectors in the Nordic countries, Møller Sneum et al. (2018) and Skytte et al. (2017) have demonstrated the negative impact of unsuitable electricity grid tariffs on district heating using $\mathrm{P} 2 \mathrm{H}$.

This study argues that coherent price signals sent to district heating operators through both electricity market prices and regulated grid tariffs will add to the flexibility provided by traditional electricity generation, power transmission, storage and demand-side management (Kirkerud et al. 2016; Tveten et al. 2016; Lund et al. 2015).

The purpose of this study is to demonstrate the limits of volumetric electricity grid tariffs in a VRE-heavy electricity system and to make recommendations for alternative tariff structures that support flexibility. While previous studies investigating alternative tariffs and flexibility quantitatively have usually left aside the requirements associated with monopoly regulation, this study covers this gap. We combine system optimization with the regulation of network industries to assess and review three alternative grid tariffs: a flat tariff, a peak-event tariff and a dynamic tariff. We test and compare them in a case study of district heating in Denmark using a representative set of heat generation technologies, storage capacity and heat demand.

Section two presents the theoretical background to network industry pricing and tariff designs, stresses the shortcoming of dominant volume-based tariffs and presents an overview of alternative tariff designs. Section three performs the quantitative analysis. Section four discusses the results of the optimization in light of the regulatory requirements. The last section presents the main conclusions and main policy implications.

\section{Electricity network regulation and tariff structure}

\subsection{Theoretical principles of electricity grid pricing}

\subsubsection{Rate-fixing in natural monopolies}

Electricity network industries are natural monopolies with decreasing unit costs. The large economies of scale and stranded costs make competition and market rules unsuited to determining optimal prices and levels of output. Electricity networks are therefore organized as a regulated monopoly, and their costs are covered through regulated tariffs. 
Economic efficiency is a major criterion for the regulation of natural monopolies. However, applying marginal cost pricing (first-best) to a natural monopoly would result in bankruptcy. A number of pricing principles have been developed to secure cost recovery for a natural monopoly without getting too far away from first-best. Ramsey-Boiteux pricing (so-called second-best pricing) was developed in the fifties. It posited that the gap between the short-term marginal cost and the tariff paid by a category of consumers must be inversely proportional to its price elasticity, meaning that consumers with low price elasticity are charged a higher tariff than the short-term marginal cost (for a detailed analysis, see Laffont and Tirole 1993). Because of the difficulties involved in determining the price elasticity of different groups of consumers, it has not been applied directly in practice. It also includes an element of discrimination between flexible and inflexible consumers that could be unacceptable with respect to criteria of fairness. Proxies are time-of-use (TOU) tariffs where inelastic consumers unable to avoid consuming during peak hours pay most of the infrastructure costs.

In current tariff practice, non-linear pricing, such as multi-part tariffs, are commonly used for both distribution and transmission grids. They are based on the network operator's cost components instead of the users' price elasticities and offer multiple combinations between different cost elements (Table 1). The principle is that consumers should pay the costs they incur, which is difficult to determine because of the large share of fixed system-wide costs.

\begin{tabular}{|l|l|l|}
\hline \multicolumn{1}{|c|}{$\begin{array}{c}\text { Expense category for the } \\
\text { grid operator }\end{array}$} & \multicolumn{1}{c|}{$\begin{array}{c}\text { Cost component in the final } \\
\text { bill }\end{array}$} & Unit \\
\hline Variable costs & Volumetric charge & EUR/MWh \\
\hline Fixed individual costs & Subscription charge & EUR/period \\
\hline Fixed system-wide costs & Capacity charge & EUR/MW \\
\hline
\end{tabular}

Table 1. Relationship between expenses categories and cost components

Fixed individual costs indicate that any new user will increase the operator's costs and correspond to a fixed fee per connection. This is the case, for example, with the meter costs. They are rather simple to introduce into the tariff structure, as the causality between user and cost is direct and is reflected in the tariff by the subscription charge, which is generally an annual or monthly fee (EUR/period). Fixed system-wide costs are more delicate to distribute as they reflect capital expenses that are mostly associated to assets with stranded cost, with no cost causality effect, meaning that this category of cost is unavoidable and remains the same regardless of the grid users. Variable costs depend on the levels of activity and the effective supply of electricity. They mostly consist of losses and should be represented in the tariff by a volumetric charge (EUR/MWh) 
Multi-part tariffs are built on known and expected network costs and are therefore subject to ex-post adjustments guaranteeing that revenue adequacy is met. Economic efficiency lies in the optimal allocation of the operator's costs among the appropriate cost components of the tariff in order to send final users the economic signals reflecting their use of the network. Accordingly, the higher the level of detail shown in the components the more cost-reflective the tariff.

The regulation of natural monopolies is also historically related to the mission and ability of public services to serve the general interest and to comply with broader social and economic requirements (European Commission 2015; Reneses et al. 2013; Honkapuro and Tuunanen 2012; Eurelectric 2013; Rodríguez Ortega et al. 2008; Berg and Tschirhart 1988; Reneses et al. 2013). For example, electricity tariffs should guarantee fairness across consumers through non-discriminatory pricing. According to this principle, all consumers belonging to the same category should be charged equally, thereby avoiding social discrimination for households and market distortions for businesses and industrials. Tariffs should also be transparent and simple enough for end-users to anticipate their bills, as well as demonstrating stability in order to reduce regulatory uncertainty and allow businesses to make their investment forecasts.

\subsubsection{Limitation of volumetric tariffs to send flexibility signals}

Currently two- to three-part tariffs are those most commonly used by European TSOs and DSOs (ENTSO-E 2017; European Commission 2015), but they usually fail to apportion fixed and variable costs adequately. Fixed costs represent on average $91 \%$ of total infrastructure costs in European distribution grids against $9 \%$ for variable costs (Reneses et al. 2013). However, the benchmark on DSOs' tariff designs realized on behalf of the European Commission shows that tariffs recover most fixed costs through a volumetric charge, regardless of the voltage level (European Commission 2015). The energy component in the tariff is dominant, with a share that represents on average $60 \%$ of the electricity bill paid by European industrial consumers and up to 100\% for small consumers (NordREG 2015; European Commission 2015).

Volumetric tariffs present two main limits. The asymmetry between the actual cost structure and the tariff design obstructs the correct signals, including that for flexibility (Eurelectric 2016; Honkapuro and Tuunanen 2012). Besides, volumetric tariffs couple the utilities' profits to their sales volumes and exacerbate the difficulties involved in implementing flexibility and energy efficiency measures in general (Gómez 2013).

Such tariffs are challenged in a future with increasing prosumption and demand response, where utilities face a volume risk, as the quantity of energy distributed may no longer be sufficient to cover their fixed costs 
(Eurelectric 2016). The question of developing new tariff designs then becomes critical for utilities (Faerber et al. 2018; Schittekatte et al. 2018; Wood et al. 2016). Accordingly, distribution grid operators are expected to play an active role in producing new designs, decoupled from the amount of volume sold, in order to secure their income flows in the long term.

The introduction of locational tariffs to accommodate network constraints in space has been widely discussed and implemented by TSOs in various countries at different scales, for example, in the Nordic countries. Time-granularity in grid tariffs would also improve the system's efficiency and attract growing interest (see 2.2.). Because of the lumpiness of network investments, achieving a direct transcription of scarcity signals in time is difficult. Nevertheless, it is argued that on the one hand appropriate alternative grid tariffs allowing a better transmission of flexibility signals in a system with a large share of VRE can strike a better balance between enhanced economic efficiency for electricity grids, revenue adequacy, fairness, simplicity and stability. On the other hand, flexibility-friendly tariffs would improve the business case for flexible technologies, notably in district heating, as well as supporting decarbonization policies.

\subsection{Overview of alternative grid tariffs in electricity networks}

In their study, Olmos and Pérez-Arriaga 2009 point out that using volume-based tariffs in transmission grids results in the absorption of tariff costs by the grid users in their bidding strategy, "therefore causing an unwanted distortion in the original market behaviour of these agents". This relationship is observed at the distribution level in district heating. Volumetric tariffs add an additional cost per unit of electricity consumed. This affects the marginal cost of producing heat irrespective of the system's condition and discriminates against the use of electricity as a resource in the heat sector compared to other resources such as gas or biomass.

The relationship between a time-based electricity tariff structure and flexibility has attracted growing interest in recent years, which is reflected in a multiplication of studies and pilot projects aimed at testing them. At the European level, Art. 15 of the Energy Efficiency Directive states that network regulation and tariffs should facilitate demand response in organized electricity markets, notably to "shift customers' demand from peak to off-peak" or to "store energy", and also they "should facilitate possibilities of dynamic pricing" from independent suppliers. On the market side, the Council of European Energy Regulators stresses that alternative tariffs must "comply with a demand response world", meaning that they should not distort the price signals from the wholesale market (CEER 2013). The interplay between time-varying electricity grid 
tariffs and retail electricity prices was simulated by Similä et al. (2011), who concluded that benefits were maximized to the distribution operator and the final user when both the tariff and the electricity price vary over time.

The survey and study realized respectively by NordREG (2015) and Evens and Kärkkäinen (2009) investigated about a dozen different time-based tariff pilots, mostly TOU tariffs for retail consumers, and showed that the main objectives in introducing these tariffs were to enhance energy efficiency, make savings on bills, reduce losses and make long-term cuts in investing in the network. Peak-load shedding at the retail level and network investment deferral were also identified as the main goals of alternative tariffs by THEMA (2013), Similä et al. (2011) and SEAS-NVE and DONG Energy (2015).

Most recent studies looking at the interplay between grid tariffs and forms of renewable energy focus on decentralized prosumers. Jargstorf et al. (2013) showed that a restructuring of volumetric tariff designs can incentivize prosumption while ensuring that the network operator recovers costs, and they analysed the results in considering a set of regulatory requirements. A growing array of literature shows how grid tariff designs can contribute to lower system peak demand in a system with a high share of DER (Higgins et al. 2014), notably in acting as an indirect subsidy for batteries (Schittekatte et al. 2018).

With respect to flexibility signals in grid tariffs, some tariffs already include time-based elements, usually in the form of seasonal or day/night block rates (Ropenus and Skytte 2007; Dupont et al. 2014; European Commission 2015). However, this time granularity does not allow the flexibility challenges linked to the growth of VRE generation to be addressed, as they are limited to expressing cost causality. Studies have elaborated on how to reflect cost causality in the grid tariff for transmission operators (Olmos and PérezArriaga 2009; Pérez-Arriaga and Smeers 2003; Rodríguez Ortega et al. 2008). They stress the fact that fixing ex ante future operating costs in using an annual charge is considered a good practice that does not interfere with market participation by the grid users and makes the market price clear. Even though they address spatial and not temporal signals, the cost decomposition method they use provides a framework in which to think about time-based tariffs. Dupont et al. 2014 propose a theoretical framework to design a cost-reflective locational dynamic tariff supporting RES integration. However, the method used to redesign the tariff structure is based on the aggregation of all the costs related to electricity consumption (energy, grid tariff and retail cost). As such, the final design corresponds more to a tariff used in a vertically integrated industry. In addition, only locational elements are embedded in the network part, thus leaving the energy price component as the only driver for flexibility. In the same vein, Schreiber et al. (2015) develop a dynamic 
pricing system based on households' entire electricity bill with no distinction between energy costs, network costs and taxes as triggers for VRE flexibility. They conclude that there is a positive effect between VRE integration and overall dynamic pricing with respect to a coherent distribution between fixed and variable costs. Kirkerud et al. (2016) relaxed the cost decomposition method in order to build a tariff and went a step further in addressing dynamic tariffs in a multi-energy context. They demonstrate the impact on flexibility of electric boilers in district heating through the introduction of different time-based tariffs, including a realtime volumetric tariff that follows the wholesale electricity market price, which is inconsistent in a vertically unbundled industry. The aggregation of the different price signals conveyed in the final electricity bill in a VRE-heavy system is discussed by Haro et al. (2017). The authors propose to use a tariff that follows the hourly average power variations in the network, thereby being consistent with greater cost-reflectivity in a relatively simple way. Kolokathis et al. 2018 stress that different tariff designs should be implemented to different groups of users and recommend that volumetric TOU or critical peak tariffs be introduced for nonresidential and flexible loads.

These studies all show that simple volumetric tariffs are limited for driving economic efficiency on the networks, triggering flexibility and enhancing system efficiency. Some of them also acknowledge the necessity to meet regulatory requirements and highlight shortcomings in the fulfilment of economic and social regulatory principles (Faerber et al. 2018; Dupont et al. 2014; Jargstorf et al. 2013; Kirkerud et al. 2016; Rodríguez Ortega et al. 2008).

In section 3, we design a set of alternative tariffs, which we then confront with the volumetric tariff currently used in Denmark.

\section{Methodology}

\subsection{Overview of district heating in Denmark}

Denmark's electricity supply is increasingly dominated by VRE (primarily wind power), which now accounts for close to $50 \%$ of total generation. District heating provides a large part of heat supply and thus offers a significant flexibility potential. CHP dominates heat supply (see Table 2). Most CHP units have invested in water tanks in order to produce electricity when prices are high and to store the hot water when it is not needed for heating. By providing additional power, district heating contributes to flexibility. In hours with a large supply of power from VRE and low demand, P2H-technologies can exploit the low electricity 
prices to offer additional demand. So far their contribution to flexibility has been marginal due to the lack of competitiveness created by high tariffs and taxes.

\begin{tabular}{lcccc}
\hline $\begin{array}{c}\text { Share of heat } \\
\text { supply }\end{array}$ & CHP & $\begin{array}{c}\text { Power-to-heat } \\
(\mathrm{P} 2 \mathrm{H})\end{array}$ & $\begin{array}{c}\text { Heat-only (HO) } \\
\text { boilers }\end{array}$ \\
\hline Denmark & $50 \%$ & $69 \%$ & $<1 \%$ & $30 \%$ \\
\hline
\end{tabular}

Source: (Energistyrelsen 2016)

Table 2. Share of district heating in heat production by technology in Denmark

The Danish electricity grid tariff is a two-part tariff where the energy component covers the costs associated with the depreciation of all assets except the meters, operating and maintenance costs, the allowed interest and part of the energy saving effort. The subscription component covers all capital and operating expenses related to the meters, part of the energy saving effort and general customer service costs. Danish DSOs are subject to income cap regulation, but can decide tariffs and their structure by themselves. The regulator can intervene if a specific tariff is considered unfair, but that only happens very seldom.

On average, the tariff follows a $75 \%$ volumetric, $25 \%$ subscription distribution rule for retail consumers. For larger consumers such as district heating using $\mathrm{P} 2 \mathrm{H}$, the volumetric charge is largely dominant. Table 3 shows the average value of both the energy and capacity charge based on a benchmark of Danish districtheating operators. The benchmark shows that the relative average share of the energy component is $97 \%$.

\begin{tabular}{lcccc}
\hline $\begin{array}{l}\text { Distribution } \\
\text { grid tariffs }- \\
10 \mathrm{kV}\end{array}$ & $\begin{array}{c}\text { Volumetric charge } \\
\text { [EUR cts./kWh] }\end{array}$ & $\begin{array}{c}\text { Subscription } \\
\text { charge } \\
\text { [EUR./year] }\end{array}$ & $\begin{array}{c}\text { Total price [EUR } \\
\text { cts./kWh] }\end{array}$ & $\begin{array}{c}\text { Share of } \\
\text { the energy } \\
\text { part }\end{array}$ \\
\hline average & 1.29 & 773.58 & 1.33 & $97 \%$ \\
median & 1.24 & 688.22 & 1.27 & $97 \%$ \\
minimum & 0.83 & 188.19 & 0.84 & $98 \%$ \\
maximum & 1.86 & 2943.75 & 2.01 & $92 \%$ \\
\hline
\end{tabular}

Table 3. Share of the variable component in the grid tariff paid in Danish district heating

The Danish electricity grid tariff is added on to the spot price paid by $\mathrm{P} 2 \mathrm{H}$ operators, which itself accounts for $13 \%$ to $44 \%$ of the final cost per heat unit (based on 2014-2015 NordPool spot prices).

Figure 1 shows the relationship between spot electricity prices and the use of the competing heat technologies. Electric boilers have been selected as representative of P2H-technologies. Heat pumps could also be included as an obvious option for district heating. However, the costs of large heat pumps are very site-specific due to the different availability of heat sources, making it meaningless to choose a representative 
unit. The cost includes fuel prices, taxes, and operating and maintenance costs for all units. Heat-only technologies such as natural gas (NG) and biomass boilers are decoupled from the electricity market. Their cost to generate heat is not affected by spot prices and remains constant. For the natural gas CHP (NG CHP), the cost falls when the electricity price increases because the price of the sold electricity is included in the cost. The CHP and electric boiler lines show how spot-price variations affect their competitiveness in the merit order and subsequent heat generation. The dashed line shows the marginal cost of electric boilers generating heat excluding the electricity grid tariff, whereas the bold line shows the marginal cost including the volumetric grid tariff. In the current situation, electric boilers are competitive during periods when spot prices are lower than EUR 5/MWh. Assuming a complete removal of the tariff, this technology could compete under spot prices of up to EUR 18/MWh.

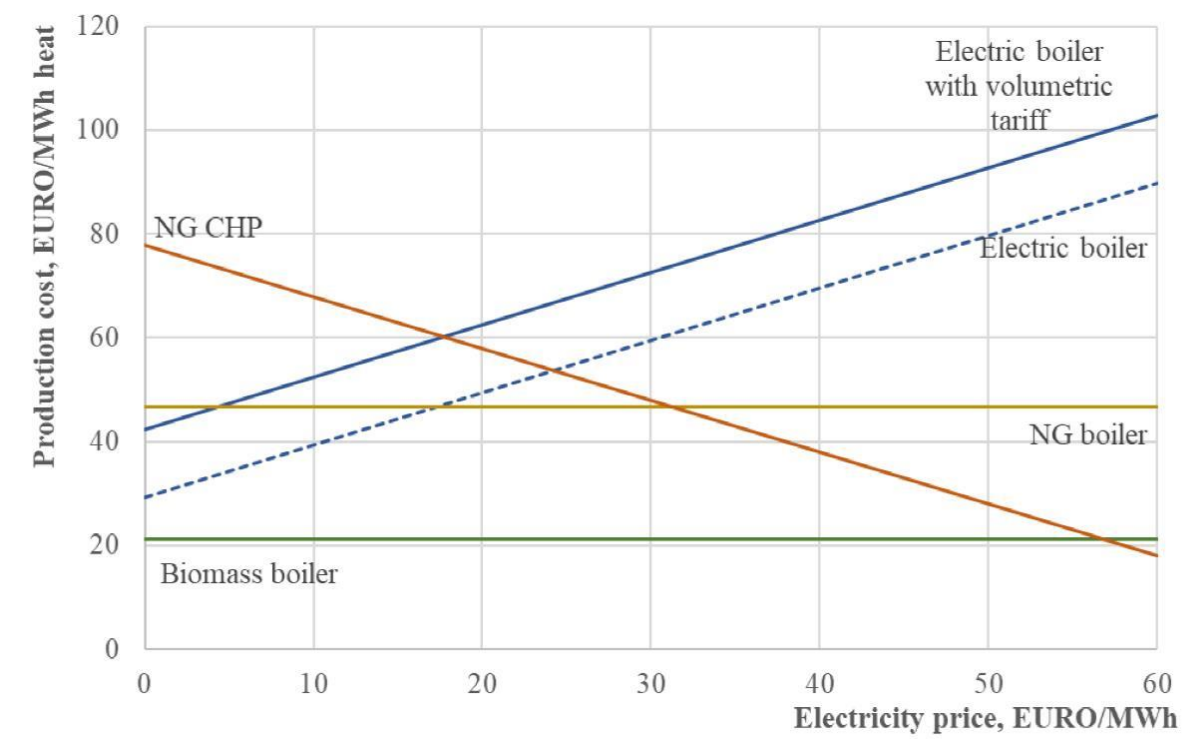

Figure 1. Optimal technology dispatch to produce heat in district heating in Denmark

\subsection{Constructing alternative grid tariffs}

One of the simplest time-based tariffs, the TOU tariff, has been used for a long time by many utilities and is now enjoying a revival. It is used in Denmark's two largest cities, Copenhagen and Aarhus, and the country’s energy authorities are currently discussing its generalization within the 3.0 Danish model. However, as the traditional TOU tariff applies a fixed time schedule it is not so relevant for a future situation with much VRE, where the occurrence of network constraints will be more stochastic. 
In this study, we go one step further and test three electricity grid tariffs. A flat capacity tariff is used to demonstrate the maximum flexibility that can be reached in the test case. To our knowledge, no alternative tariff has been designed specifically to take into account VRE variations and load. This study develops two time-based tariffs based on the residual demand to address VRE flexibility specifically: a peak-event volumetric tariff (PE) and a dynamic tariff(DT) (Figure 2).

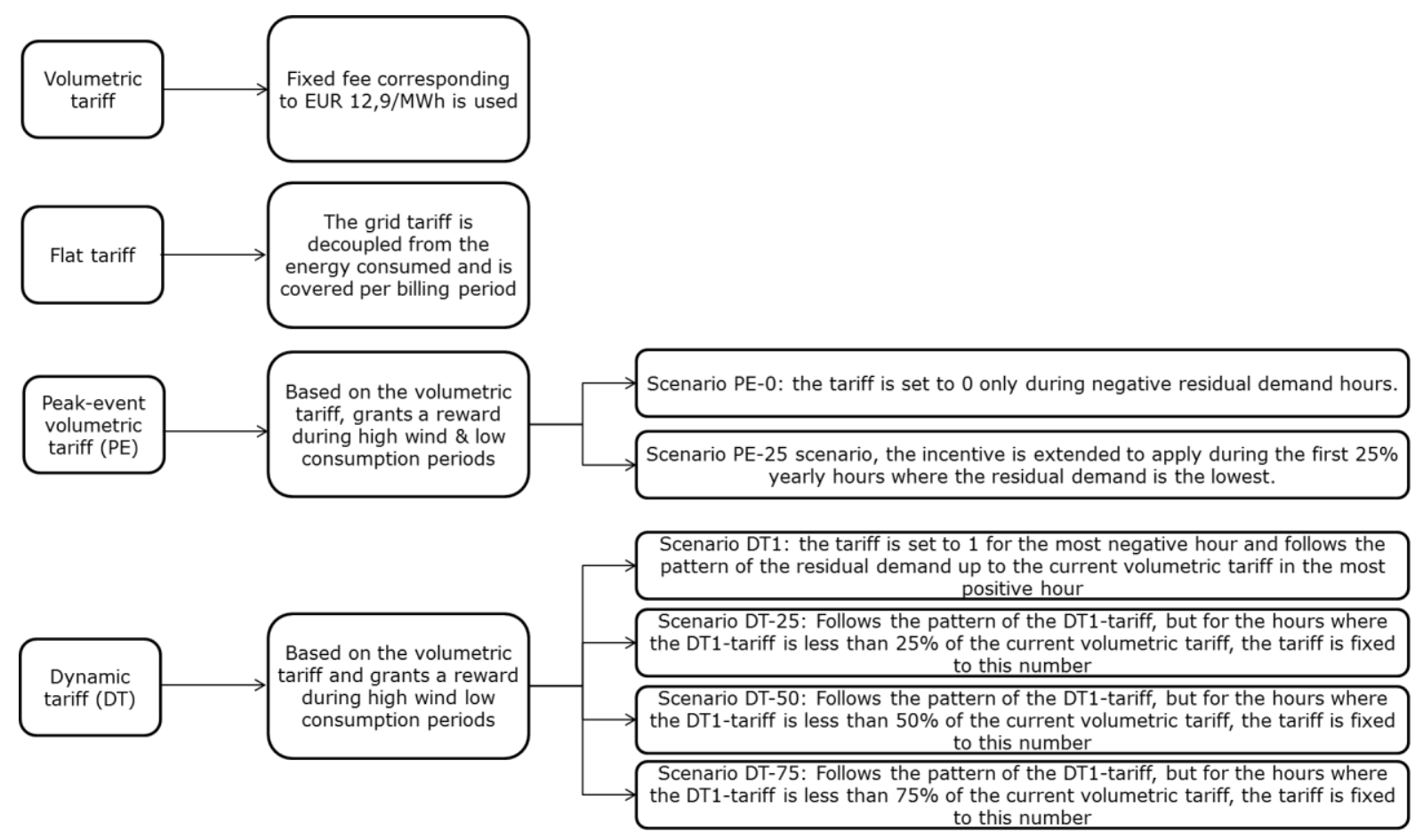

Figure 2. Overview of the tariffs

The flat tariff is a capacity-based tariff paid by billing period. It is therefore removed from the short-term hourly marginal cost for generating heat. Because this study investigates the interplay between the tariff and the marginal cost of generating heat, we assume that the capacity part is fixed by the regulatory authority in an efficient manner, and we do not specify a method of fixing it. Some studies have nevertheless specifically investigated methods setoff setting the capacity component in a cost-reflective manner (for more details, see (Passey et al. 2017 or Nijhuis et al. 2017).

Both the PE volumetric tariff and the DT are based on the current volumetric tariff and add different degrees of granularity to capture VRE fluctuations based on the residual load. The PE tariff introduces a reward mechanism that is activated to encourage consumption (or storage) during the hours when the residual demand is low or negative, while the volumetric tariff applies the rest of the time. Two scenarios with 
different levels of incentive are introduced. In PE-0, the tariff is set to 0 only during hours of negative residual demand. In the PE-25 scenario, the incentive is extended to apply during the first $25 \%$ yearly hours when residual demand is lowest. Figure 3 shows the two PE tariffs.

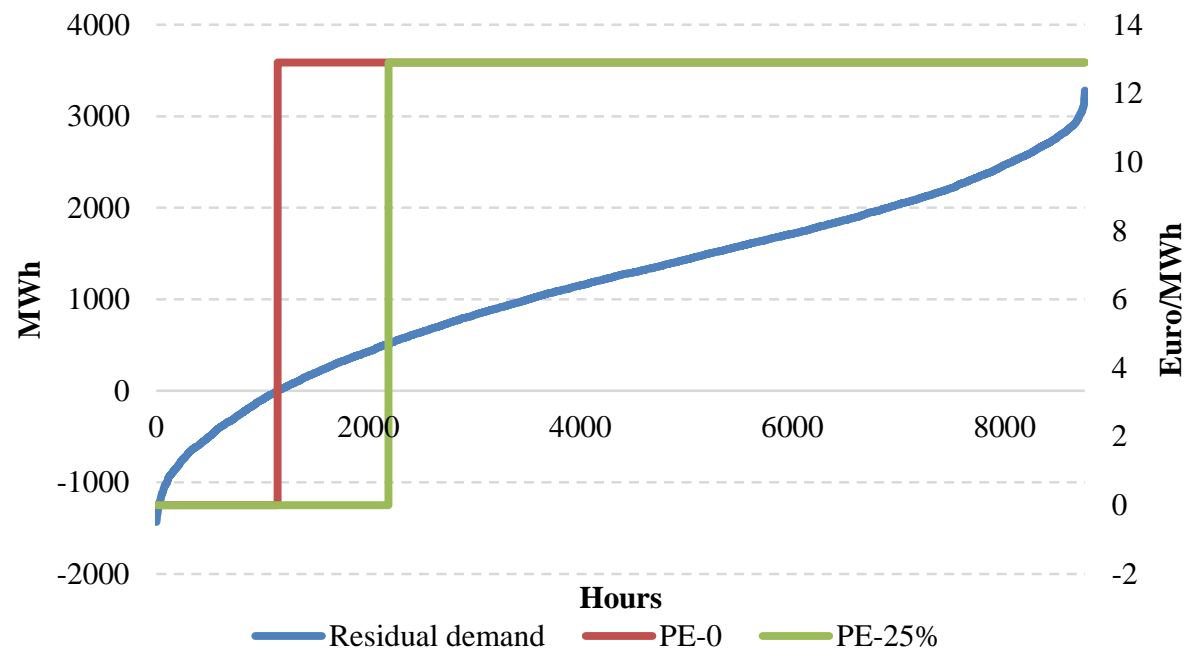

Note: The residual demand is plotted on the primary vertical axis, the tariffs on the secondary vertical axis.

Figure 3. The event-based volumetric tariff scenarios plotted with the residual demand

The DT equals a predefined minimum tariff for the most negative hours and follows the pattern of residual demand up to the volumetric tariff in the most positive hour. To increase the grid operator's income, we include an alternative dynamic tariff that follows the pattern of this tariff, but in the hours when it falls below a threshold, we fix the alternative tariff to this threshold. Our testing uses four scenarios: DT-1, DT-25\%, DT-50\% and DT-75\%. The DT-1 scenario follows the pattern of residual demand with the minimum tariff set to $1 € / M W h$, whereas the other scenarios incorporate the alternative dynamic tariff. Using scenario DT$25 \%$ as an example, the tariff is fixed to $25 \%$ of the volumetric tariff in the hours when the tariff in the DT-1 scenario is lower than this number. The dynamic tariff scenarios are shown in Figure 4. Again, the residual demand is plotted on the primary vertical axis, while the tariffs are plotted on the secondary vertical axis. 


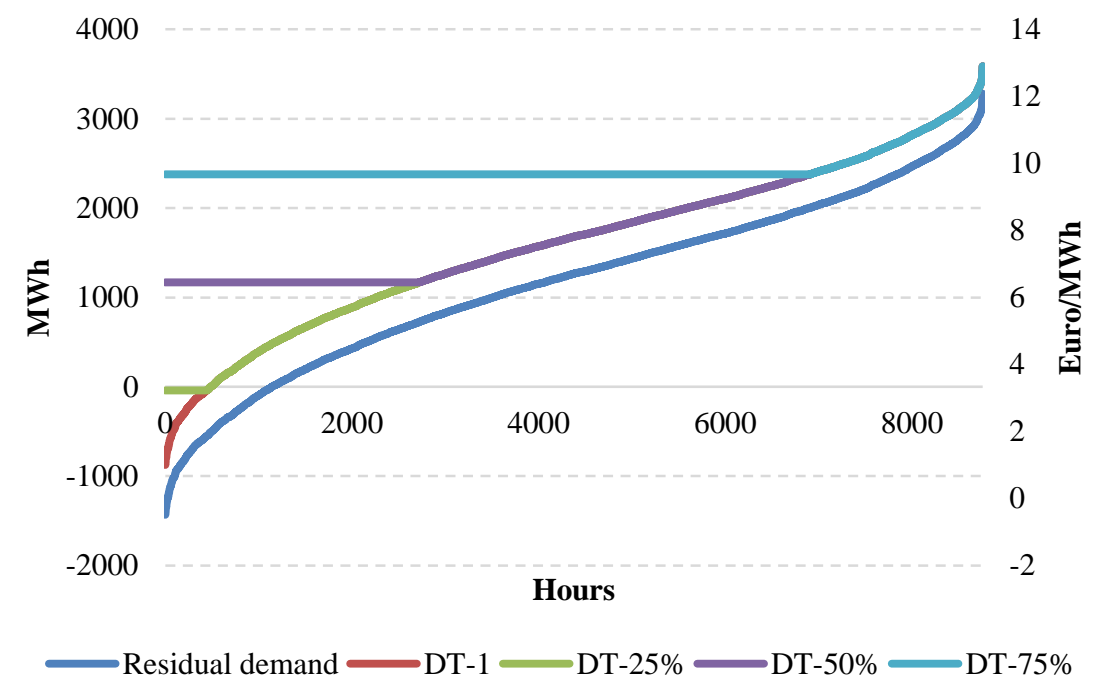

Figure 4. The dynamic tariff scenarios

\subsection{Model}

A mixed-integer programming model is developed to evaluate the consequences of applying the different tariffs in a Danish district heating system. The model minimizes the operating costs and optimizes the technology mix over a year, given specific capacities of the units delivering heat, and assuming the presence of heat storage. As the purpose of this study is to consider the impact of tariffs on the existing network, the capacities are fixed in the case study. The model is a general unit commitment model with both heat and power production. The objective function minimizes the costs of meeting the heat demand at the districtheating system level in taking into account the total cost for each technology, the start-up costs and the profit generated from the sale of electricity in the CHP. The heat demand is modelled inelastically due to the pricing in the Danish district heating system, where the price is set to cover the cost of the system in the particular area. Therefore, consumers have no incentive not to consume heat in certain hours. The electricity price is endogenous, as we assume that the specific system under consideration is too small to affect the electricity price. The nomenclature used in the mathematical model is described in Figure 5.

\begin{tabular}{|clcl|}
\hline Sets & & Parameters & \\
$I$ & Set of all units & $d_{t}$ & Demand in time period $t$ \\
$I^{H O}$ & Set of heat-only boilers & $q_{i}^{\max } / q_{i}^{\min }$ & $\begin{array}{l}\text { Maximum/minimum heat production } \\
\text { on unit } i\end{array}$ \\
$I^{P 2 H}$ & Set of electric boilers & $c_{i}^{v}$ & Heat-to-power ratio of unit $i$ \\
\hline
\end{tabular}




\begin{tabular}{|c|c|c|c|}
\hline$I^{P}$ & Set of CHP units & $s^{\max }$ & Maximum storage capacity \\
\hline$T$ & Set of time periods & $\eta^{\text {stor }}$ & Storage efficiency \\
\hline Variables & & $c_{i}^{O M}$ & $\begin{array}{l}\text { Operation and maintenance cost of unit } \\
i\end{array}$ \\
\hline$q_{i, t}$ & $\begin{array}{l}\text { Heat produced on unit } i \text { in time } \\
\text { period } t\end{array}$ & $f p_{i, t}$ & Fuel price of unit $i$ in time period $t$ \\
\hline$p_{i, t}$ & $\begin{array}{l}\text { Power produced on unit } i \text { in time } \\
\text { period } t\end{array}$ & $f t_{i, t}$ & Fuel tax of unit $i$ in time period $t$ \\
\hline $\boldsymbol{u}_{i, t}$ & Online status of unit $i$ in time period $t$ & $\tau_{i}$ & Tax exemption factor for unit $i$ \\
\hline$v_{i, t}$ & Start-up status of unit $i$ in time period $t$ & $e c_{t}$ & Volumetric tariff for time period $t$ \\
\hline$s_{t}^{\text {level }}$ & Storage level in time period $t$ & $c_{i}^{\text {start }}$ & Start-up cost per MW capacity of unit $i$ \\
\hline$s_{t}^{\text {in }} / s_{t}^{\text {out }}$ & Storage in/out-flow in time period $t$ & $e p_{t}$ & Electricity price in time period $t$ \\
\hline
\end{tabular}

Figure 5. Nomenclature used in the mathematical model

The units are given in the set I, which is split into three subsets: the heat-only boiler, $I^{H O}$, the electric boilers, $I^{P 2 H}$, and the CHP units $I^{P}$. The model is for the time periods given in the set $T$. The decision variables for each unit $i$ in each time period $t$ are: the heat produced, $\boldsymbol{q}_{\boldsymbol{i}, t}$; power produced, $\boldsymbol{p}_{\boldsymbol{i}, \boldsymbol{t}}$; on-line status (if a unit is run), $\boldsymbol{u}_{i, t}$; and start-up status, $\boldsymbol{v}_{i, t}$. For the storage facility, the decision variables for each time period are: storage level, $\boldsymbol{s}_{t}^{\text {level }}$; amount of stored heat, $\boldsymbol{s}_{t}^{\text {in }}$; and amount of heat taken out of storage, $\boldsymbol{s}_{t}^{\text {out }}$.

The heat demand is given by the parameter $d_{t}$. The heat capacity for each unit is given in the parameter $q_{i}^{\max }$, and the minimum production level is given by $q_{i}^{\min }$. The heat to power ratio is given by $c_{i}^{v}$. The storage has a maximum capacity of $s^{\max }$, and the storage efficiency (one minus the percentage loss) is given by $\eta^{\text {stor }}$. The operational and maintenance cost for each unit is given by $c_{i}^{O M}$. The fuel price is given by $f p_{i, t}$ and includes also the fuel tax, $f t_{i, t}$. A tax-exemption factor that applies to a given set of fuel is given by $\tau_{i}$. The volumetric tariff is given by the parameter $e c_{t}$ and is the element that is changed to reflect the tariffs described in subsection 3.1. The start-up cost per MW capacity of each unit is given in the parameter $c_{i}^{\text {start }}$.

The electricity price for which the produced power can be sold is given by $e p_{t}$. The model is formulated as follows:

$$
\begin{aligned}
& \text { Min. } \quad \mathrm{Z}=\sum_{i \in I^{H O} \backslash I^{P 2 H}} \sum_{t \in T}\left(\frac{f p_{i, t}}{\eta_{i}}+c_{i}^{O M}\right) \boldsymbol{q}_{\boldsymbol{i}, \boldsymbol{t}}+\left(\sum_{i \in I^{P}} \sum_{t \in T}\left(\frac{f p_{i, t}}{\eta_{i}}+c_{i}^{O M}-f t_{i} \tau_{i}\right) \boldsymbol{p}_{\boldsymbol{i}, \boldsymbol{t}}\right) \\
& +\sum_{i \in I^{P 2 H}} \sum_{t \in T}\left(\frac{f p_{i, t}+e c_{t}}{\eta_{i}}+c_{i}^{O M}\right) \boldsymbol{q}_{i, t}+\sum_{i \in I} c_{i}^{\text {start }} q_{i}^{\max } \boldsymbol{v}_{\boldsymbol{i}, \boldsymbol{t}}-\sum_{i \in I^{P}} \sum_{t \in T} e p_{t} \boldsymbol{p}_{\boldsymbol{i}, \boldsymbol{t}}
\end{aligned}
$$


S.t.

$$
\begin{gathered}
\sum_{i \in I} \boldsymbol{q}_{i, \boldsymbol{t}}+\boldsymbol{s}_{\boldsymbol{t}}^{\text {out }}=d_{t}+\boldsymbol{s}_{\boldsymbol{t}}^{\text {in }} \quad \forall t \in T \\
q_{i}^{\text {min }} \boldsymbol{u}_{\boldsymbol{i}, \boldsymbol{t}} \leq \boldsymbol{q}_{\boldsymbol{i}, \boldsymbol{t}} \leq q_{i}^{\text {max }} \boldsymbol{u}_{\boldsymbol{i}, \boldsymbol{t}} \quad \forall i \in I, t \in T \\
\boldsymbol{q}_{\boldsymbol{i}, \boldsymbol{t}} \boldsymbol{c}_{i}^{\text {v }}=\boldsymbol{p}_{\boldsymbol{i}, \boldsymbol{t}} \quad \forall i \in I^{P}, t \in T \\
\boldsymbol{u}_{\boldsymbol{i}, \boldsymbol{t}}-\boldsymbol{u}_{\boldsymbol{i}, \boldsymbol{t}-\mathbf{1}} \leq \boldsymbol{v}_{\boldsymbol{i}, \boldsymbol{t}} \quad \forall i \in I, t \in T \\
\boldsymbol{s}_{\boldsymbol{t}}^{\text {level }}=\eta^{\text {stor }} \boldsymbol{s}_{\boldsymbol{t}-\mathbf{1}}^{\text {level }}+\boldsymbol{s}_{\boldsymbol{t}}^{\text {in }}-\boldsymbol{s}_{\boldsymbol{t}}^{\text {out }} \quad \forall t \in T \\
\boldsymbol{s}_{\boldsymbol{t}}^{\text {level }} \leq s^{\text {max }} \quad \forall t \in T \\
\boldsymbol{q}_{\boldsymbol{i}, \boldsymbol{t}} \geq 0 \quad \forall i \in I, t \in T \\
\boldsymbol{p}_{\boldsymbol{i}, \boldsymbol{t}} \geq 0 \quad \forall i \in I^{P}, t \in T \\
\boldsymbol{u}_{i, t}, \boldsymbol{v}_{\boldsymbol{i}, \boldsymbol{t}} \in\{0,1\} \quad \forall i \in I, t \in T \\
\boldsymbol{s}_{\boldsymbol{t}}^{\text {level }}, \boldsymbol{s}_{\boldsymbol{t}}^{\text {in }}, \boldsymbol{s}_{\boldsymbol{t}}^{\text {out }} \geq 0 \quad \forall t \in T
\end{gathered}
$$

The objective function contains five terms (see Equation 1 and Equation 2). The first three terms reflect the three competing heat-generation technologies. Term 1 corresponds to the operational costs associated with running the $\mathrm{HO}$ boilers (fuel price, including taxes and operation and management costs). Operational costs are also used with the other technologies. The cost associated with CHP (Term two) also includes the tax exemption granted for the use of the fuel, while the cost associated with electric boilers (EB) (Term three) reflects the grid tariff cost. The last two terms in the objective function are the start-up cost and the income from electricity sales.

Equation 3 ensures that the demand is met in all time periods by including the heat-producing units and the storage in -and outflows. Equation 4 represents the maximum and minimum heat-production levels on each unit in each time period when the unit is on-line. Equation 5 ensures that the power production from the CHP units is fixed by the heat-to-power ratio. The relationship between on-line status and start-up status is ensured by Equation 6 . Equation 7 ensures that the storage level is related to the level in the previous time period and the in- and outflows, while Equation 8 keeps the storage level below the maximum level. Equations 9-12 set the limits to each variable in the model. 


\subsection{Case study}

We assume a representative district heating system in Denmark where $100 \%$ of the local heat demand is covered using a portfolio of technologies, including electric boilers, heat-only (HO) boilers powered by biomass and natural gas (NG), and a CHP powered by natural gas (Figure 6).

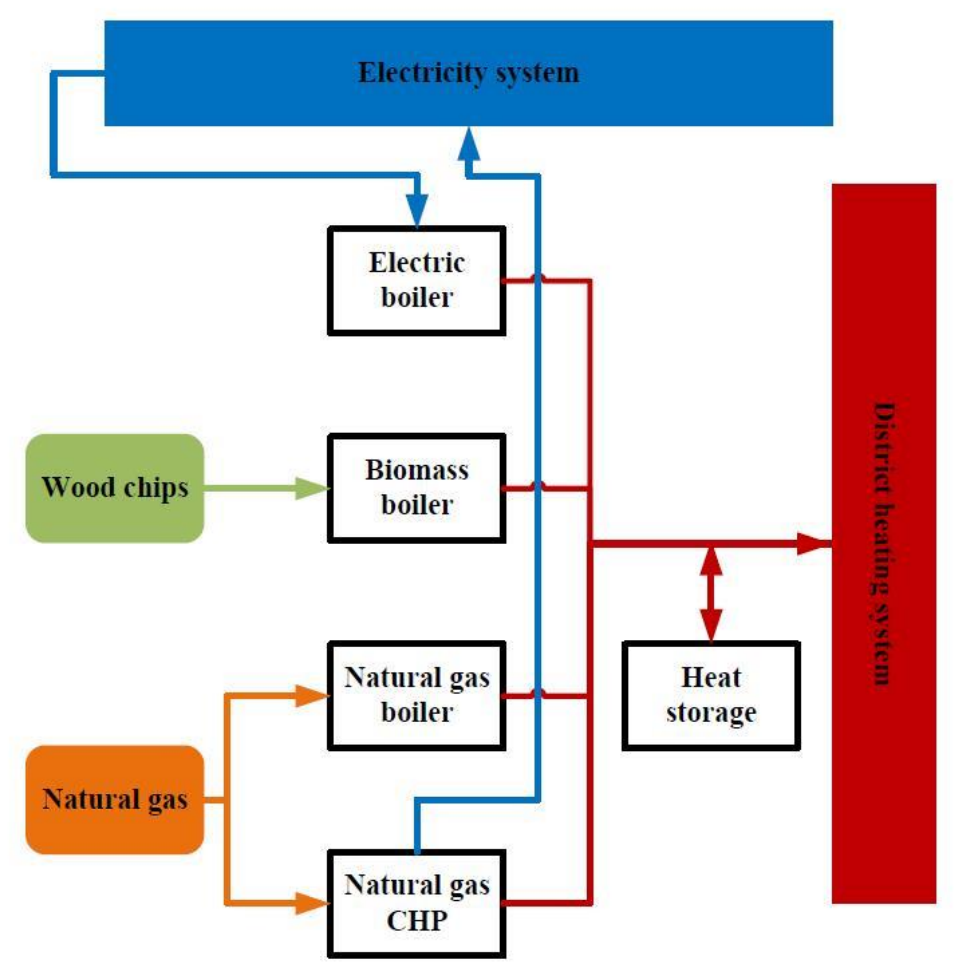

Figure 6. Representation of the district heating system

Data from the Danish 'energy producer count' made by the Danish Energy Agency (Danish Energy Agency 2016a) is used on an aggregated basis to comply with confidentiality constraints. It gives the average installed capacity for each heat-generation unit and the total heat produced in the district heating system. The total heat demand is calculated to be 18919 MWh. Table 4 shows the relevant data used (for 2016) in the construction of the test case. All data except those for start-up costs and average fuel costs are based on the technology catalogues from the Danish Energy Agency (Danish Energy Agency and Energinet.dk 2017; Danish Energy Agency 2017; Danish Energy Agency 2017b). Start-up costs are based on assumptions built upon the authors' communications with EA Energy Analyses. Average fuel costs include both taxes and the price of fuel-the fuel cost of electricity does not contain the grid tariff. The tax rates are from the Danish tax agency (SKAT 2016). The hourly price of electricity is from the Nord Pool spot market and is shown in the table as an average of the 2016 spot price. The wood chip price and the natural gas price are from (Danish 
Energy Agency 2016b). In Denmark, natural gas used for power production has a tax exemption, which can follow the so-called V-rule or E-rule (see (SKAT 2018)), in which the tax exemption is calculated by using either the heat output (V-rule) or the power output (E-rule). The producers can decide themselves which rule they will choose. In our case, the E-rule shows the greatest tax exemption, so we choose this rule for calculating the tax exemption.

\begin{tabular}{lccccc}
\hline & Unit & $\begin{array}{c}\text { Electric } \\
\text { boiler }\end{array}$ & $\begin{array}{c}\text { HO boiler, } \\
\text { wood chips }\end{array}$ & $\begin{array}{c}\text { HO boiler, } \\
\text { NG }\end{array}$ & $\begin{array}{c}\text { Spark ignition engine } \\
\text { (CHP), NG }\end{array}$ \\
\hline Capacity & $\begin{array}{c}\text { MW } \\
\text { \% of total }\end{array}$ & 4.20 & 1.70 & 6.72 & 4.95 \\
Minimum production level & 5 & 20 & 15 & 50 \\
Efficiency & $\%$ & 99 & 117.3 & 103 & 44 \\
Average fuel cost & $€ / M W h$ input & 55.1 & 22.86 & 51.61 & 51.61 \\
O\&M cost & $€ / M W h$ & 0.5 & 0.94 & 1.1 & 5.4 \\
Start-up cost & $€ / M W /$ start-up & 1 & 80 & 10 & 10 \\
Heat-to-power ratio & - & - & - & - & 0.9 \\
\hline
\end{tabular}

Table 4. Data for each heat-producing unit

Maximum storage capacity is based on the size of storage in the Fjerritslev district heating system, with 133 MW installed capacity and a yearly heat production of 70,000 MWh (Planenergi 2010). In our test case the capacity of Fjerritslev is divided by the corresponding heat production and multiplied by the heat production of the aggregated area, which results in a total capacity of $36 \mathrm{MW}$. The efficiency of the storage is based on data for a large steel tank from the Danish Energy Agency (Danish Energy Agency 2017b), where the efficiency, $\eta^{\text {stor,week }}$, over a week is $95 \%$. To arrive at this figure on an hourly basis, the efficiency for an hour, $\eta^{\text {stor }}$, is found by:

$$
\begin{gathered}
\left(\eta^{\text {stor }}\right)^{24 h \cdot 7 d}=\eta^{\text {stor,week }} \\
\Leftrightarrow \eta^{\text {stor }}=\left(\eta^{\text {stor,week }}\right)^{1 / 168} \\
\Leftrightarrow \eta^{\text {stor }}=99.97 \%
\end{gathered}
$$

We assume that the test case district heating is located in western Denmark, where wind is the most important energy source, therefore we use the electricity price for DK1 from the Nord Pool spot market. The data for wind and the production and gross consumption of electricity for DK1 are based on the Danish TSO (Energinet). The total heat production has been treated as the heat demand for the area and has been divided into an hourly time scale in accordance with a heat-demand profile provided by the Danish district heating industry organization, Dansk Fjernvarme, based on aggregated data for small district heating systems in western Denmark. 


\section{Results}

\subsection{Results of the optimisation}

The results of the optimization show that all alternative tariffs improve the business case for electric boilers. The boilers and storage capacity are run more flexibly, which arguably sends positive signals for future investments in flexible district heating systems. Electric boilers replace heat-only boilers powered with natural gas and do not impact the heat output generated by biomass energy.

Table 5 shows our results. The different tariffs are compared on the basis of their impact in terms of the increased flexibility of electric boilers expressed in running hours and participation in heat production, since such hours are correlated with VRE fluctuations and residual demand in terms of the total cost of covering the heat demand and the total yearly bill relative to the electricity grid tariff.

\begin{tabular}{|c|c|c|c|c|c|c|c|c|c|}
\hline & & BAU & Flat & PE-0 & $\begin{array}{l}\text { PE- } \\
25 \%\end{array}$ & DT-1 & $\begin{array}{l}\text { DT- } \\
25 \%\end{array}$ & $\begin{array}{l}\text { DT- } \\
\mathbf{5 0 \%}\end{array}$ & $\begin{array}{l}\text { DT- } \\
75 \%\end{array}$ \\
\hline \multirow{4}{*}{$\begin{array}{l}\text { Heat production } \\
{[\mathrm{MWh}]}\end{array}$} & EL-HO & 391 & 1357 & 1126 & 1236 & 880 & 829 & 665 & 508 \\
\hline & BIO-HO & 12209 & 12209 & 12209 & 12209 & 12209 & 12209 & 12209 & 12209 \\
\hline & NG-HO & 735 & 0 & 0 & 0 & 213 & 235 & 544 & 617 \\
\hline & NG-CHP & 5607 & 5383 & 5607 & 5495 & 5663 & 5663 & 5551 & 5607 \\
\hline \multirow{4}{*}{$\begin{array}{l}\text { Operating hours } \\
\text { [hours] }\end{array}$} & EL-HO & 106 & 511 & 349 & 417 & 254 & 240 & 186 & 137 \\
\hline & BIO-HO & 8673 & 8673 & 8673 & 8673 & 8673 & 8673 & 8673 & 8673 \\
\hline & NG-HO & 475 & 0 & 0 & 0 & 152 & 181 & 399 & 413 \\
\hline & NG-CHP & 1396 & 1340 & 1396 & 1354 & 1410 & 1410 & 1368 & 1396 \\
\hline \multicolumn{2}{|l|}{ Storage [MW] } & 3419 & 3658 & 3693 & 3693 & 3624 & 3624 & 3556 & 3487 \\
\hline \multicolumn{2}{|c|}{$\begin{array}{l}\text { Income of grid operator } \\
{[€ / \text { year }]}\end{array}$} & 5100 & $\begin{array}{c}\text { Not } \\
\text { captured }\end{array}$ & 1326 & 102 & 2907 & 3213 & 4335 & 4998 \\
\hline \multicolumn{2}{|c|}{$\begin{array}{l}\text { Total cost for heat generation } \\
\text { [€/year] }\end{array}$} & 495472 & 486058 & 488040 & 486554 & 489526 & 490022 & 492004 & 493986 \\
\hline
\end{tabular}

Table 5. Results of the optimization

The implementation of the alternative tariffs directly affects the merit order between electric boilers and natural gas-based $\mathrm{HO}$ boilers, and marginally with natural gas $\mathrm{CHP}$, while heat generation from biomass $\mathrm{HO}$ boilers still is the cheapest option, its output remaining unchanged. PE- 0 and PE-25\% tariffs have the main impact on heat storage with an increase of $8 \%$, showing the superiority of this tariff design in increasing the value of storage, against a minimum impact of $2 \%$ under the DT-75\% tariff. Figure 7 shows the variation rates in operating hours resulting from the different tariffs in comparison to the BAU volumetric tariff. The flat tariff is the most attractive option for flexibility, as it more than doubles the contribution of electric boilers throughout the year. The peak-event and dynamic tariffs also increase the business case for electric boilers and flexibility. The number of operating hours for electric boilers more than triples under the PE-0 
tariff and further increases under PE-25\%, but at a decreasing rate. The dynamic tariffs can multiply by two the running hours and generation from electric boilers in the first two scenarios, but show less significant results under scenarios DT-50 and DT-75.

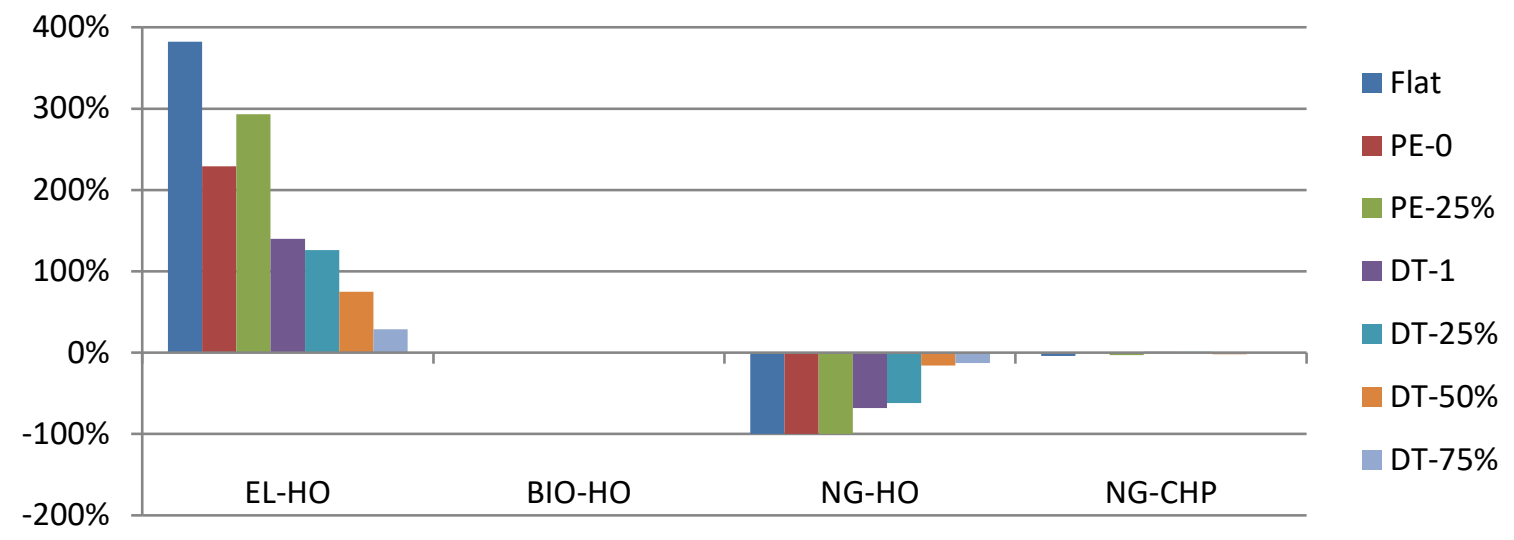

Figure 7. Impact of the alternative tariffs on district heating running hours for each technology

Figure 8 shows the total costs of running a district heating system. All alternative tariffs result in a cheaper total yearly cost to cover the heat demand at the district heating system level. The more incentivizing the tariff for using electricity in district heating the cheaper the whole heat production. Because the objective function does not capture the fixed part of the tariff, it is assumed here that each total tariff cost (fixed + variable costs) equals the BAU tariff, thereby ensuring that the grid operator always recovers the same income at the end of the exercise. From the figure, as well as from Table 5, it can be seen that the PE-25\% scenario recovers few of the grid costs through the peak-event tariff. Only approximately $8 \mathrm{MWh}$ of heat is produced when the peak-event tariff is charged. This means that the heating system is flexible enough to cover the heat demand in the peak-event hours. 


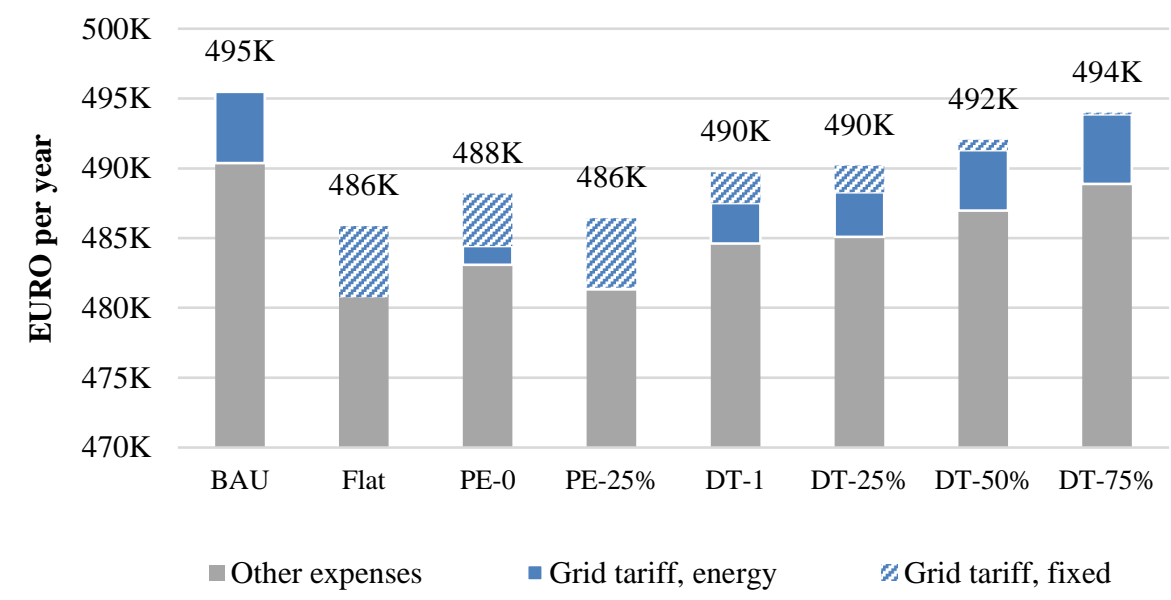

Figure 8. Impact of the tariffs on district heating system's annual cost for heat generation

\subsection{Discussion}

A thorough analysis of the tariffs goes beyond their impact on flexibility for electric boilers. Electricity grid tariffs also affect the activities of distribution grid operators and fulfil social purposes, as shown in 2.1.1. Simshauser (2015) states that: "there is no handbook or formula which prescribes the optimal tariff structure to dynamically solve for all matter of issues faced by a power system”. The final design of the tariff structure may be laborious, as some principles compete with each other as a result of the diverging interests among stakeholders. We therefore assess the impact of each tariff qualitatively on the grounds of their compliance with the regulatory objectives: revenue adequacy, economic efficiency, non-discrimination, and simplicity and stability.

In this study, it is assumed that the tariffs tested apply to all Danish district heating operators. Accordingly, the tariffs are non-discriminatory within this category of consumer and meet non-discriminatory criteria.

In the case of the volumetric tariff, the revenue generated based on the volumes of energy distributed serves to fund the capital expenses, which are comparable to a cross-subsidy between the variable and fixed cost components. This guarantees revenue adequacy in a context of low uncertainty regarding the level of demand but results in poor economic efficiency. The large success of such tariffs lies in their simplicity and the revenue stability they provide (ceteris paribus)

The flat tariff addresses the potential revenue adequacy and stability dilemma in volumetric tariffs, since the utility's income is not based on sales. It also reflects better the underlying infrastructure cost, with the fixed 
cost being dominant while equalling the volumetric tariff in terms of transparency and simplicity (the district heating operator pays a fixed periodic fee that is known in advance). The superiority of this tariff in triggering flexibility lies in its potential to drive a more rational use of electricity, as price variations in the wholesale market are less diluted than with the volumetric tariff. The flat tariff is therefore more consistent with electricity markets. However, it does not offer an optimal solution. Its main shortcoming is the difficulty in determining the appropriate level of the fixed component, which should reflect as well as possible the costs incurred by the district heating operator without discouraging electricity use. The way this tariff ultimately affects flexibility and decarbonization in district heating depends on the balance between reaching an adequate level of capacity charge without damaging the competitiveness of electricity and other energy substitutes (for more details, see Sandberg et al. (2018)).

The two time-based tariffs show the key trade-off between the incentive to act flexibly and simply on the one hand, and stability and revenue adequacy on the other hand. They apply different degrees of tariff variation. In that sense, they add a layer of complexity that is particularly marked with the dynamic tariff compared to the previous tariffs. However, because the tariffs are implemented for small industrial consumers, this risk is considered limited. The stability and revenue adequacy concerns increase with the variations in the net load and can be addressed through the inclusion of suitable regulatory tools for rate-fixing. More specifically, using adjustment mechanisms to pay back the potential losses due to flexibility measures, backed with a decoupling of profit from sales, shifts the volume risk to the final user and allows for periodic adjustments of the utility's rate case (Comnes et al. 1996; Lesh 2009). In this sense the one-year regulatory period in place in Denmark facilitates such a mechanism, as it allows yearly ex-post adjustments. Time-based tariffs also fail in distributing the grid costs optimally, though the cost-reflectivity is improved as compared to volumetric tariffs, since grid use is priced on the basis of the variable costs during periods when flexibility is needed.

\section{Conclusions and Policy Implications}

This analysis has shown that volumetric tariffs are a barrier to flexibility in the electricity sector since they limit the expression of market signals. We have focused on the activation of flexibility potentials at the interface between electricity and heat in flexible district heating systems and have assessed three alternative tariffs to trigger this flexibility. In doing so, this study tackles two key drivers for the low carbon transition in enabling demand flexibility to accommodate VREs and in promoting the green electrification of the heat 
sector. In using the Danish case, we particularly assess two time-based tariffs based on residual demand. Our analysis combines quantitative optimization with qualitative regulatory analysis to draw recommendations that encompass flexibility objectives and economic and social regulatory objectives.

We have demonstrated that the three tariffs improve flexibility at the district heating level and enhance the framework conditions for sector coupling as compared to current volumetric tariffs. We stress the trade-off between time granularity and regulatory requirements, as the level of granularity creates more complexity, as well as introducing new regulatory tools to offset the risk associated with fixed cost recovery for the utility. Within our analytical framework, the flat tariff is best suited both to increase the flexible use of electric boilers in district heating and to comply with the regulatory requirements. However, this conclusion assumes that this tariff accurately charges district heating operators based on the costs they incur to the network and that this charge does not inhibit electricity as an energy resource.

Several policy implications result from this study. We emphasize the weakness of volumetric tariffs in ensuring their main cost recovery function in a decarbonized electricity future and their negative impact on demand flexibility. This suggests that such tariffs act as a brake on the transition effort. Aligned with recent work by both academics and policy-makers, we recommend that alternative solutions be found to guarantee the continuity of utility services and to send appropriate price signals that help achieve decarbonization targets.

In this study, we have focused specifically on district heating operators, since they cover most of the heat demand in Denmark, but also because they are large consumers belonging to one and the same user category. We thereby avoid controversial discussions about the fairness of the tariffs, which belong to the political debate. However, given the development of smart grids and the ongoing challenges of VRE integration, this debate can shift to refocus on a categorization of consumers based on their flexibility potential, rather than their size and electricity usage. This suggests bridging the gap with second-best pricing, thereby allowing regulated tariffs to play an active part in the transition and treating efficient consumption as an integral component of the regulatory requirements.

Our results also stress the benefits of adopting a holistic approach in addressing decarbonization policies. The VRE flexibility issue is mainly treated in the electricity sector, thereby depriving policy-makers of solutions resulting from the activation of synergies across sectors. Particularly in the Nordic countries, this view from the "silo", highlighted by Nordic Energy Cooperation, is considered to act as an important brake on the decarbonization of other energy sectors (Ollila 2017). In our test case, we shed light on the outcome of 
the introduction of the new tariffs that support the substitution of natural gas used in heat-only boilers by green electricity, thereby facilitating the phasing out of fossil fuels in district heating.

Our main conclusions are valid if used in an electricity-only demand response framework, and they are also applicable in other industrial power-to-X applications. Our conclusions are therefore not limited to countries using district heating but would also support the electrification of the gas sector through power-to-gas. However, the tariffs investigated here are not necessarily the best to serve other consumer groups such as residential consumers, who may find the tariffs based on the net load too complex, while the tariffs with a large fixed element may be unacceptable as discriminatory for captive consumers. For some users, such as prosumers with photovoltaic solar panels, large fixed charging tariffs may be prohibitive and may induce consumers to go off-grid.

Finally, how tariffs affect flexibility is tightly linked to the relative share of grid tariffs in the final bill. Accordingly, alternative tariffs may not be suitable for all countries as a tool for flexibility. Besides, the final electricity bill also reflects a number of other charges, such as taxes and levies, which also limit price signals and flexibility. Policy-makers should consider how taxes could contribute to sending coherent signals, aligned with the transition effort.

The results of this study are consistent with the argument that the grid tariff represents an underused lever for decarbonizing energy systems. To develop the analysis further, additional research should be conducted to identify precisely how the level and structure of the fixed tariff can send appropriate signals without damaging the utilities' income. At the district heating sector level, further research is needed to determine how alternative tariffs can lower the break-even point at which investment in electric boilers becomes more profitable than competing technologies. An extension of the quantitative model to include investments in both new production units and storage is needed in order to study the impact on a future district heating system.

\section{Funding}

This work was prepared as part of the research project Flex4RES, supported by the Nordic Energy Research [contract number: 76084]. 


\section{References}

Berg, S. V \& Tschirhart, J., 1988. Natural monopoly regulation: principles and practice. Cambridge Surveys of Economic Literature Series, Cambridge University Press.

Bergaentzle, C. et al., 2017. Regulatory barriers for activating flexibility in the Nordic-Baltic electricity market. International Conference on the European Energy Market, EEM.

Borenstein, S., Jaske, M. \& Rosenfeld, A., 2002. Dynamic Pricing, Advanced Metering and Demand Response in Electricity Markets. Berkeley, U.C.,, CSEM WP 10(October), pp.1-101.

CEER, 2013. CEER Response to DRAFT THINK REPORT "Shift, not drift: Towards active demand response and beyond". Council of European Energy Regulators.,

Comnes, G.A. et al., 1996. Six useful observations for designers of PBR plans. Electricity Journal, 9(3), pp.16-23.

Danish Energy Agency, 2017. Biomass and waste plants. Excel-file. Available at: https://ens.dk/sites/ens.dk/files/Analyser/biomass_and_waste_elc_dh_tech_data_juli2017.xlsx [Accessed August 20, 2001].

Danish Energy Agency, 2016a. Energy Producer Count [Danish: Energiproducenttællingen].

Danish Energy Agency, 2016b. Forudsatninger for samfundsøkonomiske analyser på energiområdet, Available at: https://ens.dk/sites/ens.dk/files/Analyser/samfundsoekonomiske_beregningsforudsaetninger_2016_v3. pdf.

Danish Energy Agency \& Energinet.dk, 2017. Technology Data for Energy Plants, Available at: https://ens.dk/sites/ens.dk/files/Analyser/technology_data_catalogue_for_energy_plants__aug_2016_update_oct_nov_2017.pdf.

Dupont, B. et al., 2014. Demand response with locational dynamic pricing to support the integration of renewables. Energy Policy, 67, pp.344-354. Available at: http://dx.doi.org/10.1016/j.enpol.2013.12.058.

Energistyrelsen, 2016. Energistatistik 2015, Available at: https://ens.dk/sites/ens.dk/files/Statistik/energistatistik2015.pdf.

ENTSO-E, 2017. ENTSO-E Overview of transmission tariffs in Europe : Synthesis 2017,

Eurelectric, 2013. Network tariff structure for smart energy system. , (May).

Eurelectric, 2016. Network tariffs: A EURELECTRIC position paper. Available at: https://www.nve.no/energy-market-and-regulation/network-regulation/network-tariffs/ [Accessed September 14, 2016].

European Commission, 2015. Study on tariff design for distribution systems, Available at: https://ec.europa.eu/energy/sites/ener/files/documents/20150313.

Evens, C. \& Kärkkäinen, S., 2009. Pricing models and mechanisms for the promotion of demand side integration. , p.58. Available at: http://www.ece.hut.fi/enete/Pricong_models.pdf.

Faerber, L.A., Balta-Ozkan, N. \& Connor, P.M., 2018. Innovative network pricing to support the transition to a smart grid in a low-carbon economy. Energy Policy, 116(October 2017), pp.210-219. Available at: https://doi.org/10.1016/j.enpol.2018.02.010.

Gómez, T., 2013. Monopoly Regulation. In I. J. (Ed. . Pérez-Arriaga, ed. Regulation of the Power Sector. London: Springer London, pp. 151-198.

Haro, S. et al., 2017. Toward Dynamic Network Tariffs: A Proposal for Spain. Innovation and Disruption at the Grid's Edge, pp.221-239. Available at: https://www.sciencedirect.com/science/article/pii/B9780128117583000127 [Accessed October 23, 
2018].

Higgins, A. et al., 2014. Modelling future uptake of distributed energy resources under alternative tariff structures. Energy, 74(C), pp.455-463. Available at: http://dx.doi.org/10.1016/j.energy.2014.07.010.

Honkapuro, S. \& Tuunanen, J., 2012. "Tariff scheme options for distribution system operators,"

IRENA, 2018. Renewable Energy Prospects for the European Union, International Renewable Energy Agency, Abu Dabi,

Jargstorf, J., Kessels, K. \& Belmans, R., 2013. Capacity-based grid fees for residential customers. International Conference on the European Energy Market, EEM.

Kirkerud, J.G., Bolkesjø, T.F. \& Trømborg, E., 2017. Power-to-heat as a flexibility measure for integration of renewable energy. Energy, 128, pp.776-784. Available at: http://dx.doi.org/10.1016/j.energy.2017.03.153.

Kirkerud, J.G., Trømborg, E. \& Bolkesjø, T.F., 2016. Impacts of electricity grid tariffs on flexible use of electricity to heat generation. Energy, pp.1-9. Available at: http://linkinghub.elsevier.com/retrieve/pii/S0360544216309367.

Kolokathis, C., Hogan, M. \& Jahn, A., 2018. Cleaner, Smarter, Cheaper : Network tariff design for a smart future., (January), pp.1-18.

Laffont, J.. \& Tirole, J., 1993. A theory of incentives in Regulation and Procurement MIT Press., Cambridge.

Lesh, P.G., 2009. Rate Impacts and Key Design Elements of Gas and Electric Utility Decoupling: A Comprehensive Review. The Electricity Journal, 22(8), pp.65-71. Available at: https://www.sciencedirect.com/science/article/pii/S1040619009002152 [Accessed October 16, 2018].

Lislebø, O., Havskjold, M. \& Langseth, B., 2011. Fleksibilitet i fremtidens kraftsystem: Kan varmemarkedet bidra?,

Lund, H. \& Kempton, W., 2008. Integration of renewable energy into the transport and electricity sectors through V2G. Energy Policy, 36(9), pp.3578-3587.

Lund, P.D. et al., 2015. Review of energy system flexibility measures to enable high levels of variable renewable electricity. Renewable and Sustainable Energy Reviews, 45, pp.785-807. Available at: http://dx.doi.org/10.1016/j.rser.2015.01.057.

Møller-Sneum, D. et al., 2016. Framework conditions for flexibility in the district heating- electricity interface. Flex4Res project, p.66.

Møller Sneum, D. et al., 2018. Policy incentives for flexible district heating in the Baltic countries. Utilities Policy, (February), pp.1-12.

Nijhuis, M., Gibescu, M. \& Cobben, J.F.G., 2017. Analysis of reflectivity \& predictability of electricity network tariff structures for household consumers. Energy Policy, 109(January), pp.631-641.

NordREG, 2015. Tariffs in Nordic countries - survey of load tariffs in DSO grids.

Ollila, J., 2017. Nordic Energy Co-operation: Strong today - Stronger tomorrow. Nordic Council of Ministers 2017,

Olmos, L. \& Pérez-Arriaga, I.J., 2009. A comprehensive approach for computation and implementation of efficient electricity transmission network charges. Energy Policy, 37(12), pp.5285-5295.

Passey, R. et al., 2017. Designing more cost reflective electricity network tariffs with demand charges. Energy Policy, 109(April), pp.642-649.

Patrick, R.H. \& Wolak, F.A., 1997. Estimating the Customer-Level Demand for Electricity Under Real-Time Market Prices. Preliminary Draft. , (August), p.10.

Pérez-Arriaga, I.J. \& Smeers, Y., 2003. Guidelines on tariff setting. In F. Lévêque, ed. Transport pricing of 
electricity networks. Boston: Kluwer academic publishers, p. 244.

Planenergi, 2010. Fjerritslev Fjernvarmevark - Designprojekt Jammerbugt, Available at: http://fleksenergi.dk/wp-content/uploads/2015/11/FleksEnergi-Fjerritslev.pdf.

Reneses, J., Rodríguez, M.P. \& Pérez-Arriaga, I.J., 2013. Electricity Tariffs. In I. J. (Ed. . Pérez-Arriaga, ed. Regulation of the Power Sector. London: Springer, London, pp. 397-441.

Rodríguez Ortega, M.P., Pérez-Arriaga, J.I., et al., 2008. Distribution network tariffs: A closed question? Energy Policy, 36(5), pp.1712-1725.

Ropenus, S. \& Skytte, K., 2007. Regulatory review and barriers for the electricity supply system for distributed generation in the EU-15. International Journal of Distributed Energy Resources, 3, pp.243257.

Sandberg, E., Sneum, D.M. \& Trømborg, E., 2018. Framework conditions for Nordic district heating Similarities and differences, and why Norway sticks out. Energy, 149, pp.105-119.

Schittekatte, T., Momber, I. \& Meeus, L., 2018. Future-proof tariff design: Recovering sunk grid costs in a world where consumers are pushing back. Energy Economics, 70, pp.484-498. Available at: https://doi.org/10.1016/j.eneco.2018.01.028.

Schreiber, M. et al., 2015. Flexible electricity tariffs: Power and energy price signals designed for a smarter grid. Energy, 93, pp.2568-2581. Available at: http://dx.doi.org/10.1016/j.energy.2015.10.067.

SEAS-NVE \& DONG Energy, 2015. Flyt dig! Fors $\phi g$ med variable nettariffer 2015 (Move! Experiment with variable tariffs).,

Similä, L., Koreneff, G. \& Kekkonen, V., 2011. Network tariff structures in Smart Grid environment. Cleen Oy/SGEM D5.1.2 RESEARCH REPORT - VTT-R-03173-11,

Simshauser, P., 2015. Network tariffs: resolving rate instability and hidden subsidies. 10.13140/RG.2.1.2697.1048. , (May), p.36. Available at: http://aglblog.com.au/wpcontent/uploads/2014/11/No.45-Demand-Tariffs.pdf.

SKAT, 2018. Distribution of fuel between power and heat production in combined heat and power plants [Danish: Fordeling af brændsler mellem el- og varmeproduktion i kraftvarmeværker]. Available at: http://www.skat.dk/skat.aspx?oid=2061647\&chk=214955 [Accessed January 1, 2018].

SKAT, 2016. Rate change regarding energy taxes 2016 (Satsændringer vedrørende energiafgifter 2016). Available at: http://skat.dk/SKAT.aspx?oId=2186446 [Accessed March 14, 2018].

Skytte, K. et al., 2017. Barriers for District Heating as a Source of Flexibility. The Journal of Energy Markets. 10.21314/JEM.2017.161, p.19.

THEMA, 2013. Innkreving av residuale nettkostnader med AMS Påoppdrag fra Norges vassdrags- og,

Tveten, Å.G., Bolkesjø, T.F. \& Ilieva, I., 2016. Increased demand-side flexibility: market effects and impacts on variable renewable energy integration. International Journal of Sustainable Energy Planning and Management, 11, pp.33-50. Available at: http://dx.doi.org/10.5278/ijsepm.2016.11.3.

Wood, L. et al., 2016. Recovery of Utility Fixed Costs: Utility, Consumer, Environmental and Economist Perspectives. , (5), pp.1-86. 